\title{
Effect of Grain Size on the Stress Corrosion Cracking of Ultrafine Grained Cu-10 wt\% Zn Alloy in Ammonia
}

\author{
Takuma Asabe, Muhammad Rifai, Motohiro Yuasa, and Hiroyuki Miyamoto \\ Department of Mechanical Engineering, Doshisha University, Kyoto 610-0394, Japan \\ Correspondence should be addressed to Hiroyuki Miyamoto; hmiyamot@mail.doshisha.ac.jp
}

Received 26 January 2017; Accepted 11 June 2017; Published 18 July 2017

Academic Editor: Jerzy A. Szpunar

Copyright (C) 2017 Takuma Asabe et al. This is an open access article distributed under the Creative Commons Attribution License, which permits unrestricted use, distribution, and reproduction in any medium, provided the original work is properly cited.

\begin{abstract}
The effect of grain size in the micron to submicron range on the stress corrosion cracking (SCC) of Cu- $10 \mathrm{wt} \% \mathrm{Zn}$ alloys was investigated using constant-load tests in ammonia vapor. The grain size was systematically varied from $4 \mu \mathrm{m}$ to $0.12 \mu \mathrm{m}$ by either cold-rolling or equal-channel angular pressing (ECAP), followed by annealing. The time to fracture increased with decreasing grain size above $1 \mu \mathrm{m}$ but then began to decrease with decreasing grain size into the submicron range. This inverse trend in the submicron range is discussed in terms of a severe plastic deformation- (SPD-) induced ultrafine grain microstructure.
\end{abstract}

\section{Introduction}

While the effect of grain size reduction on the strength of metallic materials has been well established, its effect on corrosion is more complicated and does not appear to be explainable using a universal law such as the Hall-Petch law of the yield stress. It seems that the effect of grain size reduction on corrosion resistance is mostly positive in stainless steels [1] and aluminum alloys [2,3], whereas the effect is marginal in copper $[4,5]$ and titanium alloys [6-8]. However, there are several contradictory reports involving the same materials and environment [9-11]. The limited available literature on the effect of grain size on stress corrosion cracking (SCC) [12, 13] reports an increasing resistance to SCC with decreasing grain size. Edmund investigated the effect of grain size on the SCC of $\alpha$-brass in an ammonia environment using a constant-load test and reported increasing fracture time with decreasing grain size [14]. Additional discussion of the effect of grain size on corrosion can be found in comprehensive review papers $[15,16]$.

Severe plastic deformation (SPD) enables the reduction of grain size to the submicron range in bulk metallic materials for load-carrying structural applications [17]. The so-called ultrafine grained (UFG) materials formed by SPD exhibit unique physical and mechanical properties. For example, the strength increases enormously after ECAP and the ductility also remains relatively high or even increases in some cases [17-19]. These unique properties have frequently been attributed to deformation-induced UFG structures superimposed with the dislocation structure. The advent of SPD technology has rendered the corrosion behavior of UFG materials a more pressing issue and has brought the question of whether the dependence of corrosion properties on grain size can be extrapolated into the submicron range back to the scientific community [15].

The SCC susceptibility of UFG or nanostructured materials has been far less studied and much remains to be explored [20-31]. One limitation of SCC studies of SPD materials is that structural materials that exhibit SCC are generally highstrength alloys such as austenitic stainless steels and $\mathrm{Cu}-\mathrm{Zn}$ alloys, which are difficult to process by SPD. Fortunately, corrosion studies only require a UFG structure in the surface layer, and surface modification of even very hard materials is possible using methods such as shot peening [32] or surface mechanical attrition treatment (SMAT) [33]. Another reason for the lack of research on this topic is the very large difference in yield strength between UFG materials formed by SPD and conventional coarse-grained materials, as a result of which the standard SCC tests that apply either a common load or displacement inevitably impose different levels of strain or 


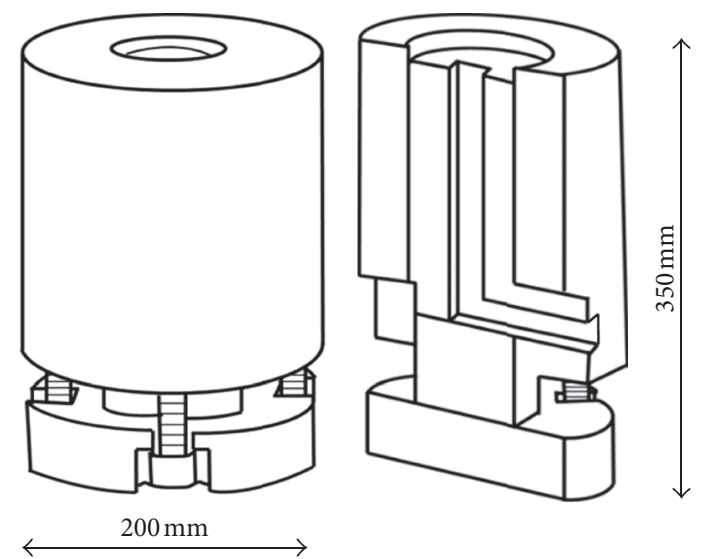

FIGURE 1: Schematic diagram and dimensions of the ECAP die.

stress in these two materials. Therefore, these two approaches may yield considerable discrepancies in experimental results, for example, in the case of the time to fracture. As an alternative approach, these two very different materials have been compared by slow-strain-rate testing (SSRT), and their susceptibility to SCC was determined from the ratio of elongation to fracture in air to that in solution [20-22, 24, 26$29,31]$. However, it remains unclear whether the susceptibility to SCC determined by SSRT reflects performance in actual service environments. In this study, we investigated the effect of grain size, ranging from fine grains to submicron grains, on the susceptibility to SCC using a model Cu-10 wt\% Zn-ammonia system under a common constant load. The objective of this study was not to compare the two extremes (UFG and conventional course-grained counterparts), as has been done in many previous studies, but to track the variation in SCC susceptibility in the transitional regime ranging from fine to submicron grains, to better understand the SCC of UFG materials from a physical point of view. As far as we know, this paper is the first to report the SCC susceptibility under constant-load tests for this range of grain sizes.

\section{Materials and Methods}

The grain sizes of commercial $\mathrm{Cu}-10 \mathrm{wt} \% \mathrm{Zn}$ alloys were systematically controlled by cold-rolling and ECAP followed by heat treatment. For ECAP, $100 \mathrm{~mm}$ long billets with an $8 \mathrm{~mm}$ square cross-section were pressed through an ECAP die for either two or eight passes by the so-called $\mathrm{Bc}$ route, in which the sample is rotated by $90^{\circ}$ around its longitudinal axis between passes. The ECAP die was deliberately designed so that harder materials such as brass and stainless steel can be pressed, as shown in Figure 1. Nevertheless, $\alpha$-brass with a higher $\mathrm{Zn}$ content, for example, $\mathrm{Cu}-30 \mathrm{wt} \% \mathrm{Zn}$, is too hard for this ECAP die, even though it is more susceptible to SCC and would have been an appropriate material for the present study. Thus, the choice of $\mathrm{Cu}-10 \mathrm{wt} \% \mathrm{Zn}$ was a compromise between the applicability to ECAP and susceptibility to SCC. Cold-rolling was carried out to a $50 \%$ reduction. After
TABLE 1: Processing recipes and grain size.

\begin{tabular}{lccc}
\hline Sample & Deformation & Annealing & Grain size $(\mu \mathrm{m})$ \\
\hline 1 & None & None & 38.0 \\
2 & CR 50\% & $673 \mathrm{~K}-60 \mathrm{~min}$ & 12.6 \\
3 & CR 50\% & $623 \mathrm{~K}-60 \mathrm{~min}$ & 3.30 \\
4 & ECAP 2 pass & $623 \mathrm{~K}-15 \mathrm{~min}$ & 1.10 \\
5 & ECAP 2 pass & $623 \mathrm{~K}-10 \mathrm{~min}$ & 0.71 \\
6 & ECAP 2 pass & $623 \mathrm{~K}-5 \mathrm{~min}$ & 0.44 \\
7 & ECAP 8 pass & $473 \mathrm{~K}-10 \mathrm{~min}$ & 0.15 \\
8 & ECAP 8 pass & $473 \mathrm{~K}-1 \mathrm{~min}$ & 0.12 \\
9 & ECAP 8 pass & & 0.12 \\
\hline
\end{tabular}

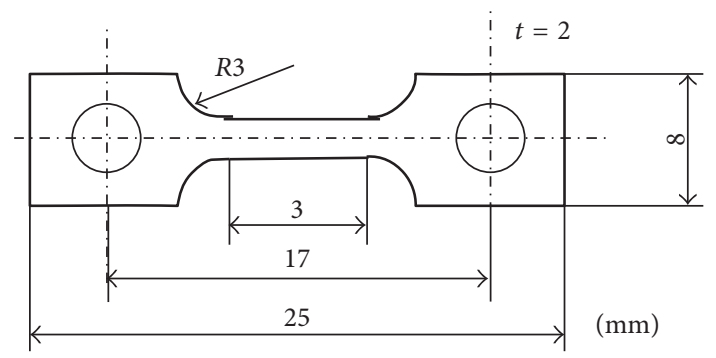

FIGURE 2: SCC specimen dimensions.

ECAP and cold-rolling, the samples were then annealed in an electronic furnace as summarized in Table 1, leading to grain sizes ranging from $0.12 \mu \mathrm{m}$ to $38 \mu \mathrm{m}$. Grain size was estimated using the intercept method, and twins were ignored following the rule of grain size measurement of copper and copper alloys described in JIS0501.

The susceptibility to SCC was evaluated in constant-load tests using a cantilever-type apparatus (Figure 2) for specimens with a yield stress above $290 \mathrm{MPa}$. A common constant stress of $280 \mathrm{MPa}$ was applied to all SCC specimens regardless of their yield stress and was selected based on our previous studies [25], which indicated that the susceptibility to SCC was much higher in as-ECAPed UFG Cu-10 wt\% $\mathrm{Zn}$ than in the coarse-grained same alloys. The dog-bone specimens shown in Figure 3 were placed in a chamber in which a $14 \%$ ammoniacal solution was placed in the bottom to fill the chamber with ammonia vapor. The time to fracture was recorded by a stopwatch placed under the edge of the beam. The microstructure and fracture surface were examined by transmission electron microscopy (TEM, JSM 2100F) and field-emission-type scanning electron microscopy (FE-SEM, JSM-FE7001).

\section{Results and Discussion}

Nominal stress-strain curves obtained from tensile tests are shown in Figure 4. ECAPed materials had typical stress-strain curves with a high tensile strength and little strain hardening capability. Thus, they exhibited necking at the onset of plastic deformation. The tensile stress exceeded $600 \mathrm{MPa}$, much greater than that of pure copper (approximately $450 \mathrm{MPa}$ 


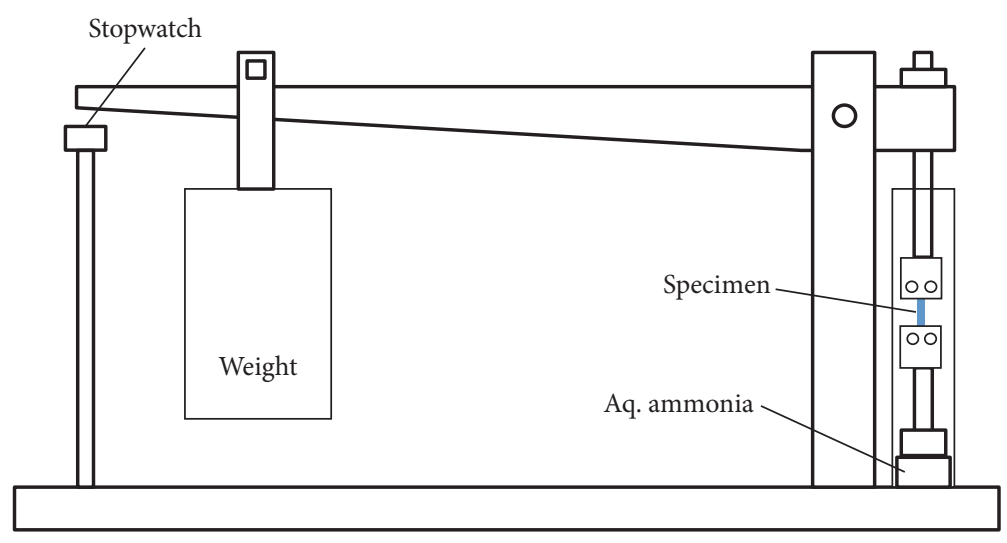

FIGURE 3: Schematic diagram of the constant-load SCC test.

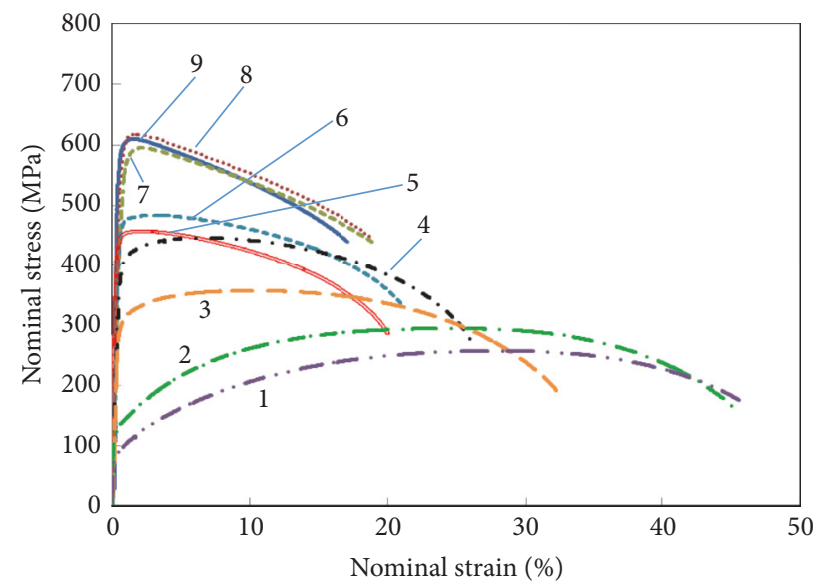

FIgURE 4: Nominal stress-strain curves of tensile tests. Numbers 1-9 correspond to the sample numbers in Table 1.

after 8 passes of ECAP). This higher tensile stress was mainly caused by solid-solution hardening and a lower stacking fault energy (SFE). Cu-10 wt\% $\mathrm{Zn}$ has an SFE of $35 \mathrm{~mJ} / \mathrm{m}^{2}$, which is much lower than that of pure $\mathrm{Cu}\left(78 \mathrm{~mJ} / \mathrm{m}^{2}\right)$ [34]. Microstructures observed by TEM and SEM are shown in Figure 5, and the processing routes and resulting grain sizes are summarized in Table 1 . The minimum grain size of $0.12 \mu \mathrm{m}$ was achieved after 8 passes of ECAP and is somewhat smaller than that achieved with pure copper $[5,31]$ and pure aluminum [35] in our previous studies. This smaller grain size achieved by SPD is associated with a lower SFE, and several studies have demonstrated that the minimum grain size achieved by SPD scales with the SFE [36-39]. The larger grain size shown in Figure 5 was obtained by recrystallization and/or grain growth using appropriate combinations of ECA/cold-rolling and annealing. Whereas a relatively uniform grain size was observed in samples processed by ECAP, samples processed by cold-rolling were less uniform, indicating that continuous grain growth occurred in the former case while discontinuous recrystallization occurred in the latter. Several studies have reported that UFG structures with a high fraction of high-angle grain boundaries (HAGBs) exhibit continuous grain growth during annealing after a very high strain is imposed by SPD, whereas discontinuous grain growth or recrystallization tends to occur when the HAGB fraction is lower and less strain is imposed by SPD [40-44]. The relationship between yield stress and the reciprocal root of grain size is shown in Figure 6. Hall-Petch relationship can be divided into two regions with different slopes: Region I with grain sizes larger than $1 \mu \mathrm{m}$ and Region II with smaller grain sizes. The slope corresponds to the constant $k$ in the Hall-Petch relationship, represented as $\sigma_{y}=\sigma_{o}+$ $k / \sqrt{d}$, where $\sigma_{y}$ is the yield stress, $\sigma_{o}$ is a constant, and $d$ is the grain size. The constant $k$ was estimated to be $0.40 \mathrm{MPam}^{1 / 2}$, which is not far from $0.27 \mathrm{MPam}^{1 / 2}$ reported by Armstrong et al. [45]. A transition of Hall-Petch slope with decreasing grain size in the submicron range was reported for UFG aluminum processed by ARB [46]. The lower slope for grain sizes smaller than $1 \mu \mathrm{m}$ was estimated to be 0.07 and attributed to residual mobile dislocations inside the grains that carry plastic strain. For larger grain sizes after longer annealing times, the slope becomes steeper because of reduced density of mobile dislocations inside the grains [46]. This discussion was based on the assumption that highangle grain boundaries act as sinks of mobile dislocations, consuming them during post-SPD annealing [47]. Similarly, in Region II in our studies, some residual mobile dislocations may carry plastic strain. However, in comparison with pure copper and pure aluminum with a higher SFE, dislocations are extended into Shockley partial dislocations with stacking faults and are difficult to be absorbed into grain boundaries, as discussed later.

In the SCC tests, the specimens were covered with a black tarnish film, which is well known to be a thick brittle copper oxide $\left(\mathrm{Cu}_{2} \mathrm{O}\right)$ that causes intergranular SCC under tensile stress [48-50]. In $\mathrm{Cu}-\mathrm{Zn}$ alloys with less than $20 \mathrm{wt} \%$ Zn, intergranular SCC tends to occur, whereas alloys with more than $20 \mathrm{wt} \% \mathrm{Zn}$ tend to exhibit transgranular SCC $[51,52]$. Cracks propagated in the tarnish film and formed at a higher rate on grain boundaries than within grains. Residual dislocations along the grain boundaries may enhance the 


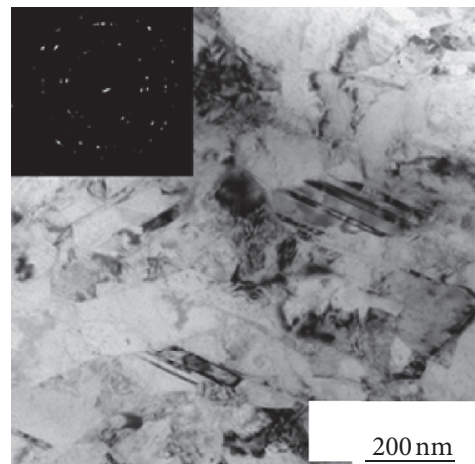

(a)

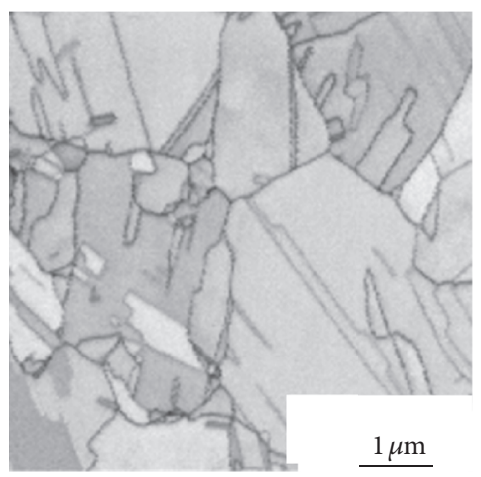

(d)

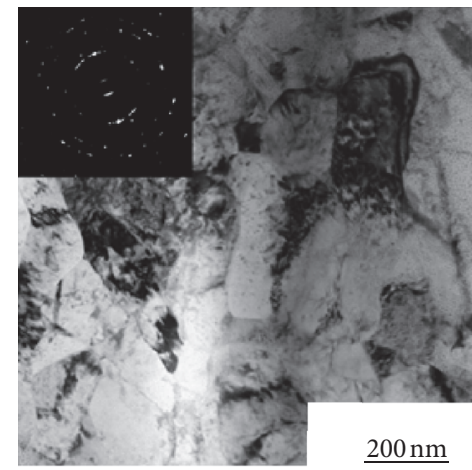

(b)

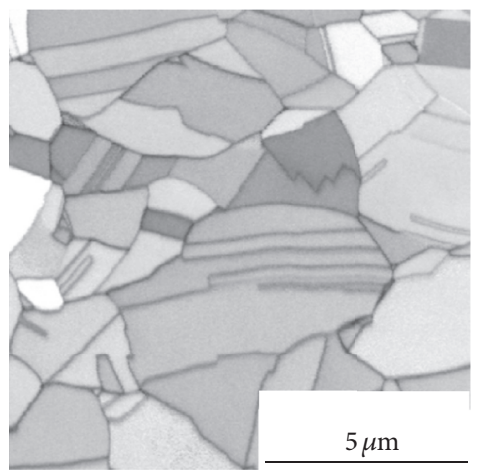

(e)

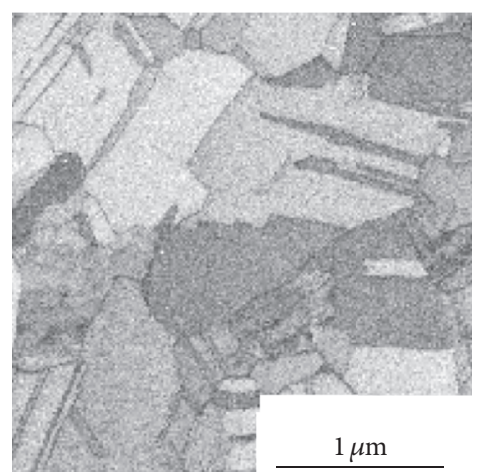

(c)

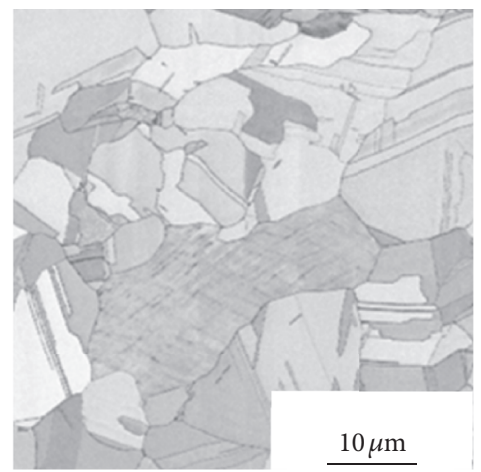

(f)

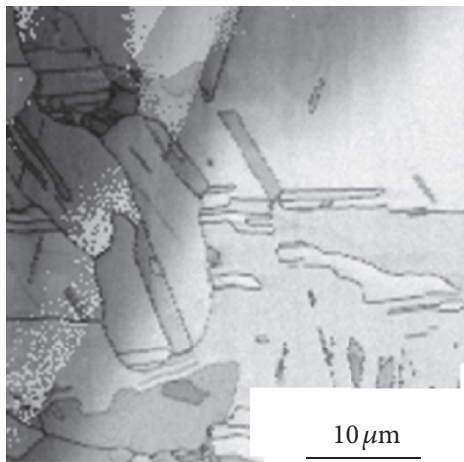

(g)

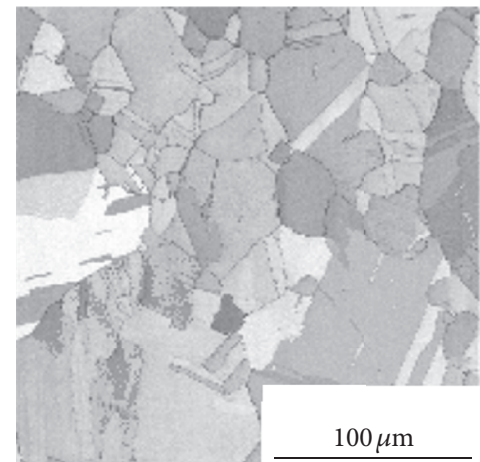

(h)

Figure 5: Microstructure after ECAP/cold-rolling and final annealing of (a) sample 8, (b) sample 7, (c) sample 6, (d) sample 5, (e) sample 4, (f) sample 3, (g) sample 2, and (h) sample 1.

reactivity of the grain boundaries with ammonia and the susceptibility to IGSCC. Figure 7 shows times to fracture obtained in SCC tests as a function of the inverse square root of grain size. Data for $\mathrm{Cu}-30 \mathrm{wt} \% \mathrm{Zn}$ in ammonia from Edmund [14] is also plotted in the figure. As with the yield stress shown in Figure 6, the variation can be divided into two regimes, with a border at $1 \mu \mathrm{m}$. Considering Edmund's data for $\mathrm{Cu}-30 \mathrm{wt} \% \mathrm{Zn}$ with large grains, it seems reasonable that the time to fracture increases with decreasing grain size from the conventional coarse grain regime down to $1 \mu \mathrm{m}$ (Region I) but then decreases with decreasing grain size in Region II. The positive trend in Region I can be explained on the basis of the assumption that an intergranular crack initiates and propagates when local stress concentration by dislocation accumulation at the grain boundary reaches a certain critical value, so at smaller grain sizes, a higher applied stress is required to activate enough dislocations [53]. The changes in SCC susceptibility for grain sizes smaller than $1 \mu \mathrm{m}$ (Region II) may be closely associated with the change in the Hall-Petch slope and can be attributed to residual dislocations, mobile or immobile, in the grains. These dislocations reside along grain boundaries or are trapped at the grain boundaries in a nonequilibrium state [54] and enhance the reactivity of grain boundaries in a corrosive environment in Region II, rendering the susceptibility less dependent on grain size. In our previous studies of UFG pure copper, 


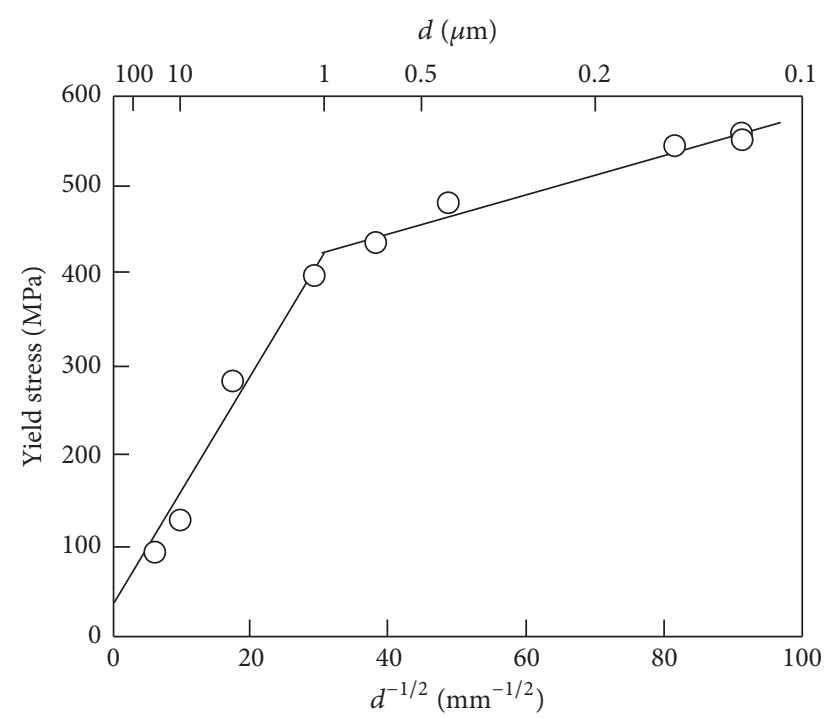

FIGURE 6: Relationship between yield stress and the inverse square root of grain size.

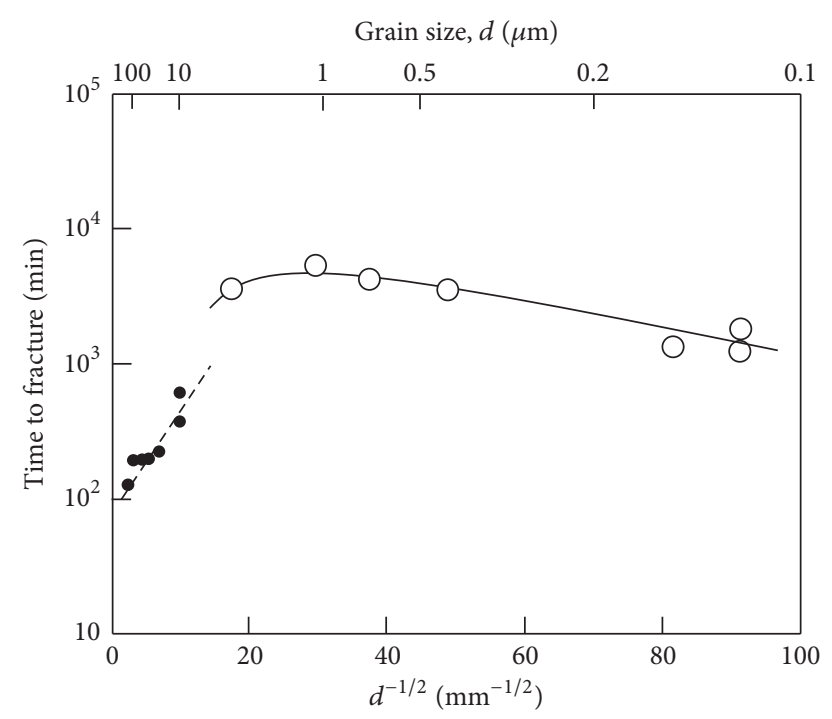

- $\mathrm{Cu}-30 \mathrm{wt} \% \mathrm{Zn}[14]$

FIGURE 7: Relationship between time to fracture and the inverse square root of grain size in the SCC tests.

very short annealing for 90 seconds at $200^{\circ} \mathrm{C}$ relaxed the nonequilibrium grain boundaries to their equilibrium state with little grain growth $[5,31,55,56]$. However, the extended dislocations with stacking faults in $\mathrm{Cu}-\mathrm{Zn}$ alloys are expected to be difficult to be absorbed into the grain boundaries as a result of the lower stacking energy and therefore may remain in the grains during annealing for longer times at higher temperatures. Furthermore, the nonequilibrium grain boundaries may be more stable due to $\mathrm{Zn}$ segregation, and some may remain in Region II [57-59]. A common constant stress of $280 \mathrm{MPa}$ was applied to all specimens, so the applied stress normalized by yield stress, $\sigma_{a} / \sigma_{\mathrm{ys}}$, was lower in specimens with a smaller grain size, which have a higher yield strength. This means that even though the dislocation activity under macroscopic elastic deformation is lower in these materials, they are more susceptible to SCC.

Grain boundary sliding is considered to be one possible mode of plastic deformation in UFG materials $[18,60]$ and has been observed at room temperature in UFG pure aluminum by atomic force microscopy [61]. Film rupture facilitated by grain boundary sliding at the crack tip may enhance the susceptibility to IGSCC under a constant load. The present results are compatible with our previous studies that employed compact specimens of $\mathrm{Cu}-10 \mathrm{wt} \% \mathrm{Zn}$, in which the threshold stress was lower and the time to fracture was higher in UFG samples than in their counterparts with larger grain sizes [25].

Macroscopically, all of the SCC specimens fractured in a brittle manner with little plastic deformation. SEM fractographs of coarse-grained sample 1 and UFG sample 9 are shown in Figures 8(a) and 8(b). Microscopic observation at higher magnification revealed an intergranular mode of fracture in both samples (Figures 8(c) and 8(d)). Since the grain size was very small and the fracture surface was readily covered by a tarnish film, it was difficult to obtain clear evidence of IGSCC by SEM observation.

In addition to grain size, grain boundary structure is another important factor influencing IGSCC resistance [6264], and several attempts have been made to alleviate SCC by controlling the grain boundary character distribution (GBCD) or by an alternative approach called grain boundary engineering (GBE) [65-68]. Ideally, the grain size and grain boundary character distribution should both be considered when characterizing the SCC of UFG materials by SPD. Therefore, SPD still has potential for high SCC resistance materials through the equilibration and control of grain boundary character distribution.

\section{Conclusions}

In this work, the effect of decreasing grain size into the submicron regime on the SCC of $\mathrm{Cu}-10 \mathrm{wt} \% \mathrm{Zn}$ alloys in ammonia was investigated using a constant-load test, leading to the following conclusions:

(1) The yield stress obtained by tensile tests increased with decreasing grain size, but the tendency decreased for grain sizes smaller than $1 \mu \mathrm{m}$. Thus, the HallPetch relationship can be divided into two regions with different slopes, with a lower slope for grain sizes smaller than $1 \mu \mathrm{m}$.

(2) The time to fracture by SCC increased with decreasing grain size down to $1 \mu \mathrm{m}$ but then decreased with further decreases in grain size into the submicron scale. In other words, there was a critical grain size above which the susceptibility began to increase, and this grain size matched the grain size that divides the two Hall-Petch relationships. 

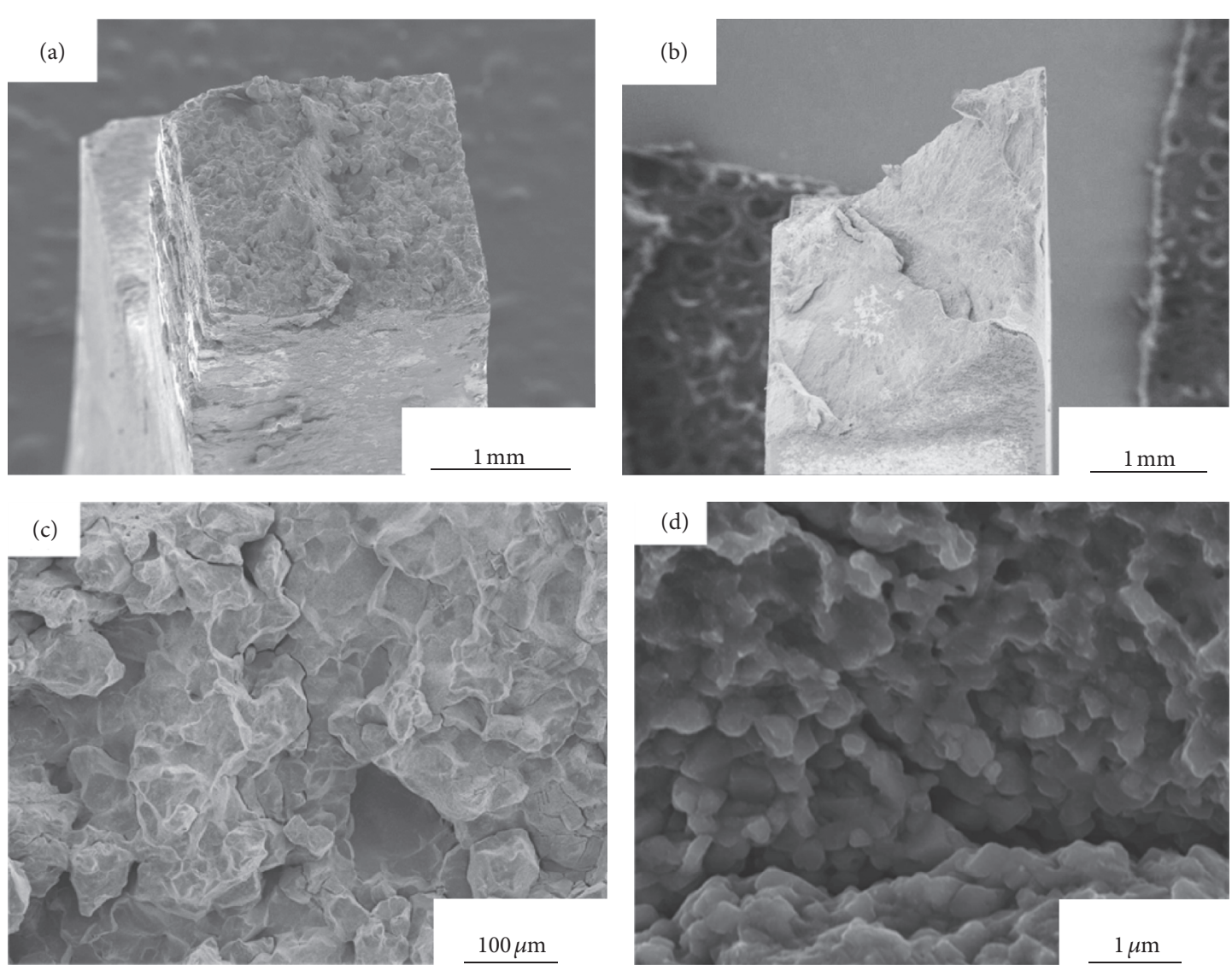

Figure 8: Fracture surfaces after SCC tests of (a), (c) sample 1, and (b), (d) sample 9 in (a), (b) macroscopic appearance, and (c), (d) microscopic observation.

(3) Stress corrosion cracks propagated intergranularly regardless of grain size. SPD-induced grain boundaries have a high sensitivity to chemical reaction and intergranular SCC.

\section{Conflicts of Interest}

The authors declare that there are no conflicts of interest regarding the publication of this paper.

\section{Acknowledgments}

This work was financially supported by JSPS KAKENHI Grant no. 26420748 and a grant-in-aid from the Japan Copper and Brass Association.

\section{References}

[1] A. Di Schino and J. M. Kenny, "Effects of the grain size on the corrosion behavior of refined AISI 304 austenitic stainless steels," Journal of Materials Science Letters, vol. 21, no. 20, pp. 1631-1634, 2002.

[2] K. D. Ralston, N. Birbilis, and C. H. J. Davies, "Revealing the relationship between grain size and corrosion rate of metals," Scripta Materialia, vol. 63, no. 12, pp. 1201-1204, 2010.
[3] K. D. Ralston, D. Fabijanic, and N. Birbilis, "Effect of grain size on corrosion of high purity aluminium," Electrochimica Acta, vol. 56, no. 4, pp. 1729-1736, 2011.

[4] B. Hadzima, M. Janeček, R. J. Hellmig, Y. Kutnyakova, and Y. Estrin, "Microstructure and corrosion behaviour of ultrafinegrained copper," Materials Science Forum, vol. 503-504, pp. 883$888,2006$.

[5] H. Miyamoto, K. Harada, T. Mimaki, A. Vinogradov, and S. Hashimoto, "Corrosion of ultra-fine grained copper fabricated by equal-channel angular pressing," Corrosion Science, vol. 50, no. 5, pp. 1215-1220, 2008.

[6] N. P. Gurao, G. Manivasagam, P. Govindaraj, R. Asokamani, and S. Suwas, "Effect of texture and grain size on bio-corrosion response of ultrafine-grained titanium," Metallurgical and Materials Transactions A: Physical Metallurgy and Materials Science, vol. 44, no. 12, pp. 5602-5610, 2013.

[7] H. S. Kim and W. J. Kim, "Annealing effects on the corrosion resistance of ultrafine-grained pure titanium," Corrosion Science, vol. 89, no. C, pp. 331-337, 2014.

[8] H. S. Kim, S. J. Yoo, J. W. Ahn, D. H. Kim, and W. J. Kim, "Ultrafine grained titanium sheets with high strength and high corrosion resistance," Materials Science and Engineering A, vol. 528, no. 29-30, pp. 8479-8485, 2011.

[9] O. Jilani, N. Njah, and P. Ponthiaux, “Transition from intergranular to pitting corrosion in fine grained aluminum processed by equal channel angular pressing," Corrosion Science, vol. 87, pp. 259-264, 2014. 
[10] A. Korchef and A. Kahoul, "Corrosion behavior of commercial aluminum alloy processed by equal channel angular pressing," International Journal of Corrosion, vol. 2013, Article ID 983261, 11 pages, 2013.

[11] D. Song, A. B. Ma, J. H. Jiang, P. H. Lin, and J. Shi, "Improving corrosion resistance of pure $\mathrm{Al}$ through ECAP," Corrosion Engineering Science and Technology, vol. 46, no. 4, pp. 505-512, 2011.

[12] A. Morris and C. Bridgeport, "Stress-corrosion cracking of annealed brass," Transactions of the American Institute of Mining and Metallurgical Engineering, vol. 89, pp. 256-275, 1930.

[13] T. C. Tsai and T. H. Chuang, "Role of grain size on the stress corrosion cracking of 7475 aluminum alloys," Materials Science and Engineering: A, vol. 225, no. 1-2, pp. 135-144, 1997.

[14] G. Edmund, "Season cracking of brass, symposium on stress corrosion cracking of metals, A.S.T.M. and A.I.M.E. (1945) pp. 67-89," 1945.

[15] H. Miyamoto, "Corrosion of ultrafine grained materials by severe plastic deformation, an overview," Materials Transactions, vol. 57, no. 5, pp. 559-572, 2016.

[16] K. D. Ralston and N. Birbilis, "Effect of grain size on corrosion: a review," Corrosion, vol. 66, no. 7, 2010.

[17] R. Z. Valiev, R. K. Islamgaliev, and I. V. Alexandrov, "Bulk nanostructured materials from severe plastic deformation," Progress in Materials Science, vol. 45, no. 2, pp. 103-189, 2000.

[18] R. Z. Valiev, I. V. Alexandrov, Y. T. Zhu, and T. C. Lowe, "Paradox of strength and ductility in metals processed by severe plastic deformation," Journal of Materials Research, vol. 17, no. 1, pp. 58, 2002.

[19] C. C. Koch, "Optimization of strength and ductility in nanocrystalline and ultrafine grained metals," Scripta Materialia, vol. 49, no. 7, pp. 657-662, 2003.

[20] G. R. Argade, W. Yuan, K. Kandasamy, and R. S. Mishra, "Stress corrosion cracking susceptibility of ultrafine grained AZ31," Journal of Materials Science, vol. 47, no. 19, pp. 6812-6822, 2012.

[21] G. R. Argade, N. Kumar, and R. S. Mishra, "Stress corrosion cracking susceptibility of ultrafine grained Al-Mg-Sc alloy," Materials Science and Engineering A, vol. 565, pp. 80-89, 2013.

[22] Y. H. Jang, S. S. Kim, S. Z. Han, C. Y. Lim, and C. J. Kim, "Corrosion and stress corrosion cracking behavior of equal channel angular pressed oxygen-free copper in $3.5 \% \mathrm{NaCl}$ solution," Journal of Materials Science, vol. 41, no. 13, pp. 42934297, 2006.

[23] H. Miyamoto, T. Kishi, T. Mimaki, A. Vinogradov, and S. Hashimoto, "Stress corrosion cracks propagation in ultrafine grain copper fabricated by an equal-channel angular pressing," in Ultrafine Grained Materials, IV, Y. T. Zhu, T. G. Langdon, Z. Horita, M. J. Zehetbauer, S. L. Semiatin, and Lowe T. C., Eds., p. 337, John Wiley \& Sons, Inc., Hoboken, NJ, USA, 2002.

[24] H. Miyamoto, T. Mimaki, A. Vinogradov, and S. Hashimoto, "Mechanical, thermal and stress-corrosion properties of ultrafine grain copper," Annales de Chimie Science des Matériaux, vol. 27, pp. S197-S206, 2002.

[25] H. Miyamoto, A. Vinogradov, and S. Hashimoto, "Susceptibility to stress corrosion cracking in ammonia of nanostructured $\mathrm{Cu}-10 w \mathrm{w} \% \mathrm{Zn}$ alloy produced by severe plastic deformation," Materials Science Forum, vol. 584-586, pp. 887-892, 2008.

[26] H. Nakano, S. Oue, S. Taguchi, S. Kobayashi, and Z. Horita, "Stress-corrosion cracking property of aluminum-magnesium alloy processed by equal-channel angular pressing," International Journal of Corrosion, vol. 2012, Article ID 543212, 2012.
[27] S. A. Nikulin, S. O. Rogachev, A. B. Rozhnov, M. V. Gorshenkov, V. I. Kopylov, and S. V. Dobatkin, "Resistance of alloy Zr-2.5\% $\mathrm{Nb}$ with ultrafine-grain structure to stress corrosion cracking," Metal Science and Heat Treatment, vol. 54, no. 7-8, pp. 407-413, 2012.

[28] M. M. Sharma and C. W. Ziemian, "Pitting and stress corrosion cracking susceptibility of nanostructured Al-Mg alloys in natural and artificial environments," Journal of Materials Engineering and Performance, vol. 17, no. 6, pp. 870-878, 2008.

[29] A. Turnbull, K. Mingard, J. D. Lord et al., "Sensitivity of stress corrosion cracking of stainless steel to surface machining and grinding procedure," Corrosion Science, vol. 53, no. 10, pp. 33983415, 2011.

[30] A. Vinogradov, H. Miyamoto, T. Mimaki, and Hashimoto S., "Corrosion, stresss corrosion cracking and fatigue of ultra-fine grain copper fabricated by severe plastic deformation," Annales de Chimie Science des Matériaux, vol. 27, pp. 65-75, 2002.

[31] T. Yamasaki, H. Miyamoto, T. Mimaki, A. Vinogradov, and S. Hashimoto, "Stress corrosion cracking susceptibility of ultrafine grain copper produced by equal-channel angular pressing," Materials Science and Engineering A, vol. 318, no. 1-2, pp. 122128, 2001.

[32] B. N. Mordyuk, G. I. Prokopenko, M. A. Vasylyev, and M. O. Iefimov, "Effect of structure evolution induced by ultrasonic peening on the corrosion behavior of AISI-321 stainless steel," Materials Science and Engineering A, vol. 458, no. 1-2, pp. 253261, 2007.

[33] T. Balusamy, S. Kumar, and T. S. N. S. Narayanan, "Effect of surface nanocrystallization on the corrosion behaviour of AISI 409 stainless steel," Corrosion Science, vol. 52, no. 11, pp. 38263834, 2010.

[34] Y. H. Zhao, Y. T. Zhu, X. Z. Liao, Z. Horita, and T. G. Langdon, "Tailoring stacking fault energy for high ductility and high strength in ultrafine grained $\mathrm{Cu}$ and its alloy," Applied Physics Letters, vol. 89, no. 12, Article ID 121906, 2006.

[35] H. Miyamoto, K. Ota, and T. Mimaki, "Viscous nature of deformation of ultra-fine grain aluminum processed by equalchannel angular pressing," Scripta Materialia, vol. 54, no. 10, pp. 1721-1725, 2006.

[36] K. Edalati and Z. Horita, "High-pressure torsion of pure metals: influence of atomic bond parameters and stacking fault energy on grain size and correlation with hardness," Acta Materialia, vol. 59, no. 17, pp. 6831-6836, 2011.

[37] C. X. Huang, W. Hu, G. Yang et al., "The effect of stacking fault energy on equilibrium grain size and tensile properties of nanostructured copper and copper-aluminum alloys processed by equal channel angular pressing," Materials Science and Engineering A, vol. 556, pp. 638-647, 2012.

[38] S. Komura, Z. Horita, M. Nemoto, and T. G. Langdon, "Influence of stacking fault energy on microstructural development in equal-channel angular pressing," Journal of Materials Research, vol. 14, no. 10, pp. 4044-4050, 1999.

[39] J. Wan, K. Zhou, J. Lu, X. Xu, and Y. Jian, "Influence of stacking fault energy on grain-refining during severe plastic deformation," Chinese Journal of Mechanical Engineering, vol. 44, pp. 126-131, 2008.

[40] S. S. Hazra, E. V. Pereloma, and A. A. Gazder, "Microstructure and mechanical properties after annealing of equal-channel angular pressed interstitial-free steel," Acta Materialia, vol. 59, no. 10, pp. 4015-4029, 2011. 
[41] J. Lian, R. Z. Valiev, and B. Baudelet, "On the enhanced grain growth in ultrafine grained metals," Acta Metallurgica Et Materialia, vol. 43, no. 11, pp. 4165-4170, 1995.

[42] A. Takayama, X. Yang, H. Miura, and T. Sakai, "Continuous static recrystallization in ultrafine-grained copper processed by multi-directional forging," Materials Science and Engineering A, vol. 478, no. 1-2, pp. 221-228, 2008.

[43] W. Q. Cao, A. Godfrey, W. Liu, and Q. Liu, "Annealing behavior of aluminium deformed by equal channel angular pressing," Materials Letters, vol. 57, no. 24-25, pp. 3767-3774, 2003.

[44] W. Q. Cao, A. Godfrey, W. Liu, and Q. Liu, "EBSP study of the annealing behavior of aluminum deformed by equal channel angular processing," Materials Science and Engineering A, vol. 360, no. 1-2, pp. 420-425, 2003.

[45] R. Armstrong, I. Codd, R. M. Douthwaite, and N. J. Petch, "The plastic deformation of polycrystalline aggregates," Philosophical Magazine, vol. 7, no. 73, pp. 45-58, 1962.

[46] D. Terada, S. Inoue, and N. Tsuji, "Microstructure and mechanical properties of commercial purity titanium severely deformed by ARB process," Journal of Materials Science, vol. 42, no. 5, pp. 1673-1681, 2007.

[47] X. Huang, N. Hansen, and N. Tsuji, "Hardening by annealing and softening by deformation in nanostructured metals," Science, vol. 312, no. 5771, pp. 249-251, 2006.

[48] T. R. Pinchback, S. P. Clough, and L. A. Heldt, "Stress corrosion cracking of alpha brass in a tarnishing ammoniacal environment: fractography and chemical analysis," Metallurgical Transactions A, vol. 6, no. 8, pp. 1479-1483, 1975.

[49] E. Mattsson, "Stress corrosion in brass considered against the background of potential/pH diagrams," Electrochimica Acta, vol. 3, no. 4, pp. 279-291, 1961.

[50] R. Nishimura and T. Yoshida, "Stress corrosion cracking of $\mathrm{Cu}-30 \% \mathrm{Zn}$ alloy in Mattsson's solutions at $\mathrm{pH} 7.0$ and 10.0 using constant load method-a proposal of SCC mechanism," Corrosion Science, vol. 50, no. 4, pp. 1205-1213, 2008.

[51] P. R. Swann, "Dislocation substructure vs transgranular stress corrosion susceptibility of single phase alloys," Corrosion, vol. 19, no. 3, pp. 102t-114t, 1963.

[52] D. Tromans and J. Nutting, "Stress Corrosion cracking of facecentered-cubic alloys," Corrosion, vol. 21, no. 5, pp. 143-160, 1965.

[53] H. Vehoff, H. Stenzel, and P. Neumann, "Experiments of bicrystals concerning the influence of localized slip on the nucleation and growth of intergranular stress corrosion cracks," Zeitschrift fuer Metallkunde/Materials Research and Advanced Techniques, vol. 78, no. 8, pp. 550-556, 1987.

[54] M. W. Grabski and R. Korski, "Grain boundaries as sinks for dislocations," Philosophical Magazine, vol. 22, no. 178, pp. 707715, 2006.

[55] A. Vinogradov, T. Mimaki, S. Hashimoto, and R. Valiev, "On corrosion of ultra-fine grained copper produced by equi-channel angular pressing," Materials Science Forum, vol. 312-314, pp. 641-646, 1999.

[56] V. Y. Gertsman, R. Birringer, R. Z. Valiev, and H. Gleiter, “On the structure and strength of ultrafine-grained copper produced by severe plastic deformation," Scripta Metallurgica et Materiala, vol. 30, no. 2, pp. 229-234, 1994.

[57] S. Lartigue and L. Priester, "Stability of extrinsic grain boundary dislocations in relation with intergranular segregation and precipitation," Acta Metallurgica, vol. 31, no. 11, pp. 1809-1819, 1983.
[58] W. Łojkowski and M. W. Grasbaski, "On material purity influence on the spreading temperature of grain boundary dislocations," Scripta Metallurgica, vol. 13, no. 6, pp. 511-514, 1979.

[59] W. Lojkowski, J. W. Wyrzykowski, and J. Kwiecinski, "Interpretation of grain boundary nonequilibrium in terms of geometrically necessary and statistically stored dislocations," Journal de Physique Colloque, vol. C1-51, no. 1, p. C1-239, 1990.

[60] J. May, H. W. Höppel, and M. Göken, "Strain rate sensitivity of ultrafine-grained aluminium processed by severe plastic deformation," Scripta Materialia, vol. 53, no. 2, pp. 189-194, 2005.

[61] N. Q. Chinh, P. Szommer, Z. Horita, and T. G. Langdon, "Experimental evidence for grain-boundary sliding in ultrafinegrained aluminum processed by severe plastic deformation," Advanced Materials, vol. 18, no. 1, pp. 34-39, 2006.

[62] M. Yamashita, T. Mimaki, S. Hashimoto, and S. Miura, "Misorientation dependence of susceptibility to intergranular StressCorrosion-Cracking in symmetrical fbffk110fbfft-tilt $\mathrm{Cu}-9$ at. \%Al alloy bicrystals," Scripta Metallurgica, vol. 22, no. 7, pp. 1087-1091, 1988.

[63] M. Yamashita, T. Mimaki, S. Hashimoto, and S. Miura, "Stress corrosion cracking of [110] and [100] tilt boundaries of $\alpha-\mathrm{Cu}-$ Al alloy," Philosophical Magazine A, vol. 63, no. 4, pp. 707-726, 1991.

[64] V. Y. Gertsman and S. M. Bruemmer, "Study of grain boundary character along intergranular stress corrosion crack paths in austenitic alloys," Acta Materialia, vol. 49, no. 9, pp. 1589-1598, 2001.

[65] K. T. Aust, U. Erb, and G. Palumbo, "Interface control for resistance to intergranular cracking," Materials Science and Engineering A, vol. 176, no. 1-2, pp. 329-334, 1994.

[66] C. Cheung, U. Erb, and G. Palumbo, "Application of grain boundary engineering concepts to alleviate intergranular cracking in Alloys 600 and 690," Materials Science and Engineering A, vol. 185, no. 1-2, pp. 39-43, 1994.

[67] Y. Pan, B. L. Adams, T. Olson, and N. Panayotou, "Grainboundary structure effects on intergranular stress corrosion cracking of Alloy X-750," Acta Materialia, vol. 44, no. 12, pp. 4685-4695, 1996.

[68] D. C. Crawford and G. S. Was, "The Role of grain boundary misorientation in intergranular cracking of Ni-16Cr-9Fe in 360 -C argon and high-Purity water," Metallurgical Transactions A, vol. 23, no. 4, pp. 1195-1206, 1992. 

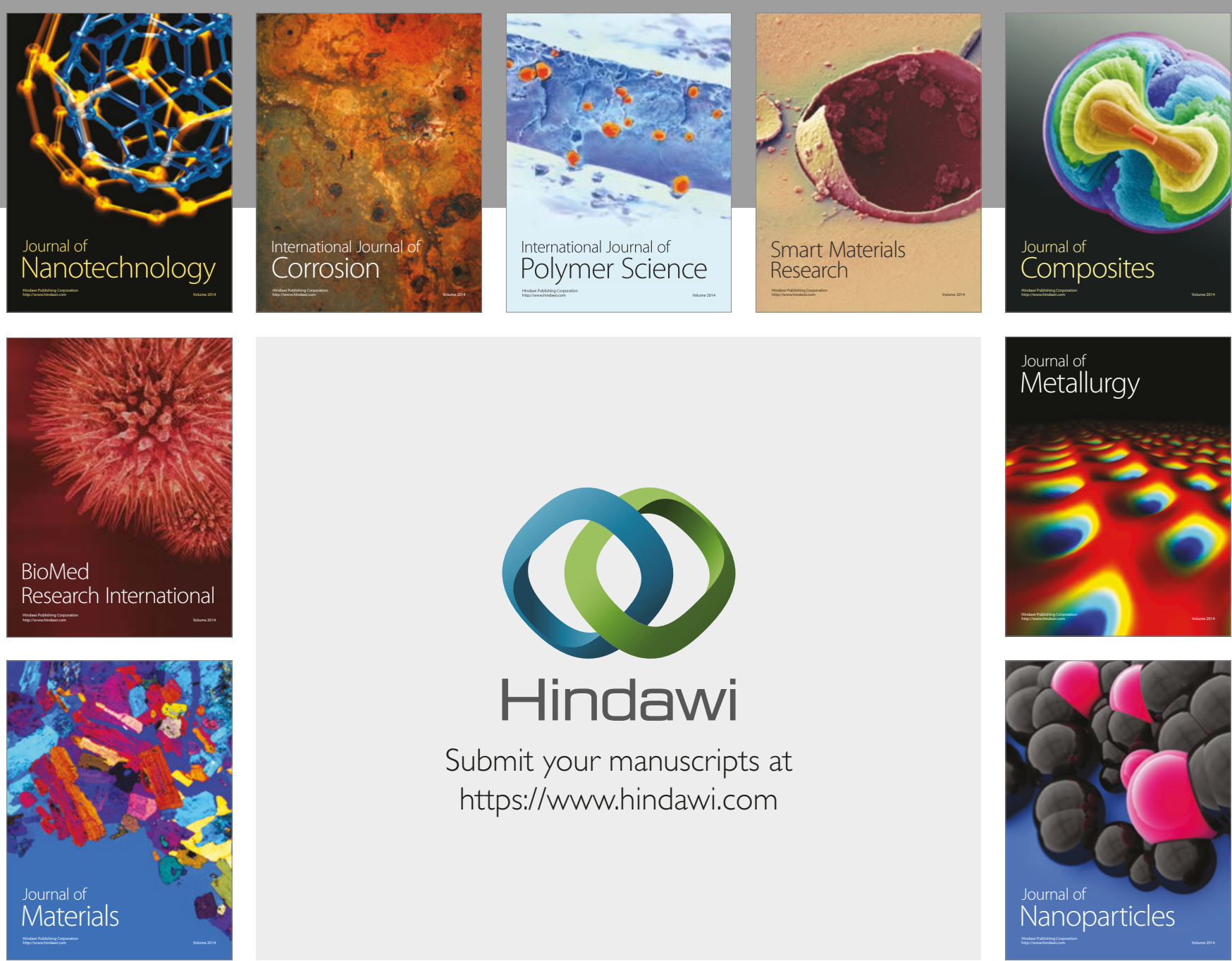

\section{Hindawi}

Submit your manuscripts at

https://www.hindawi.com
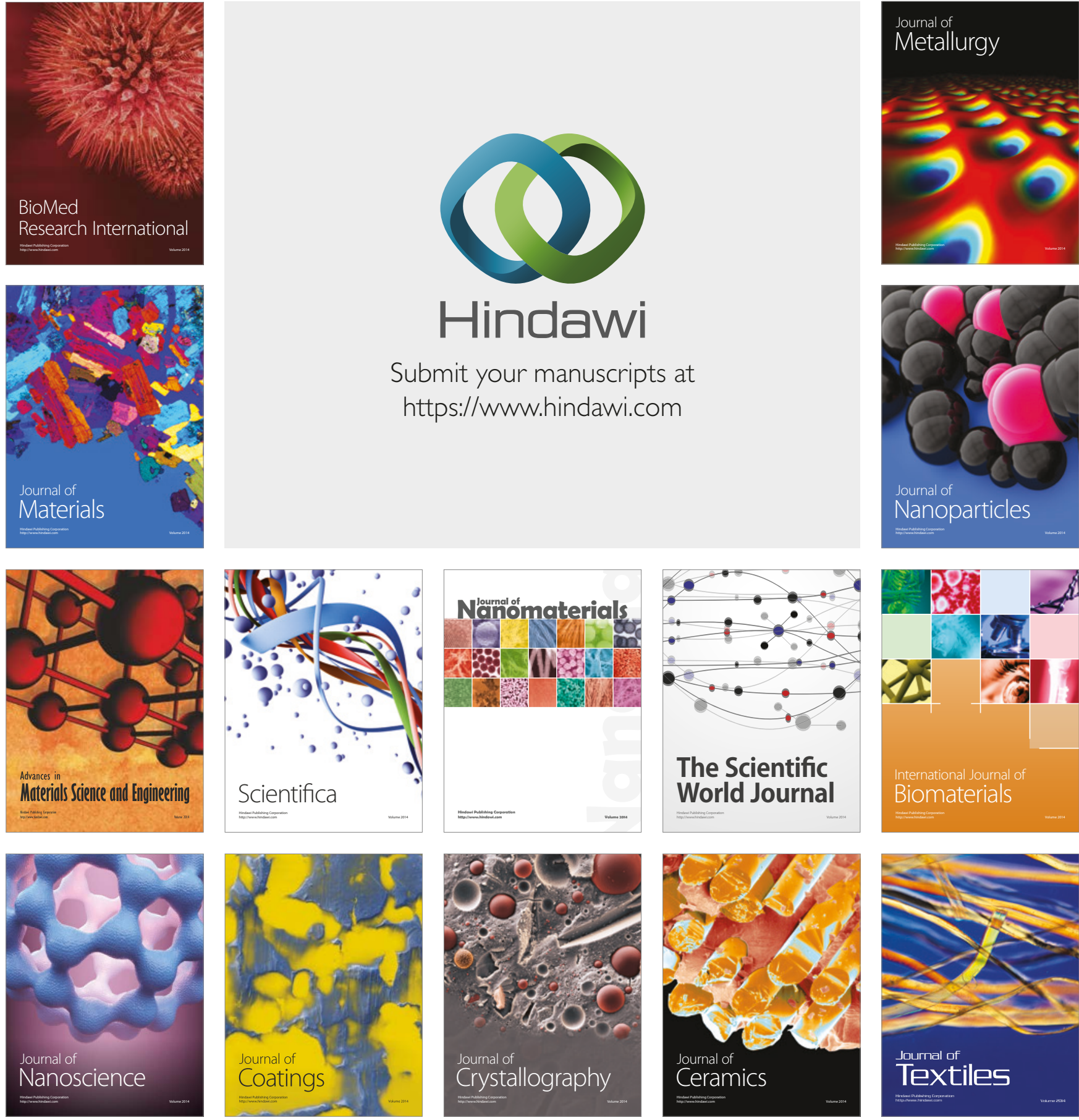

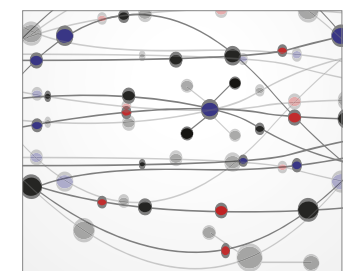

The Scientific World Journal
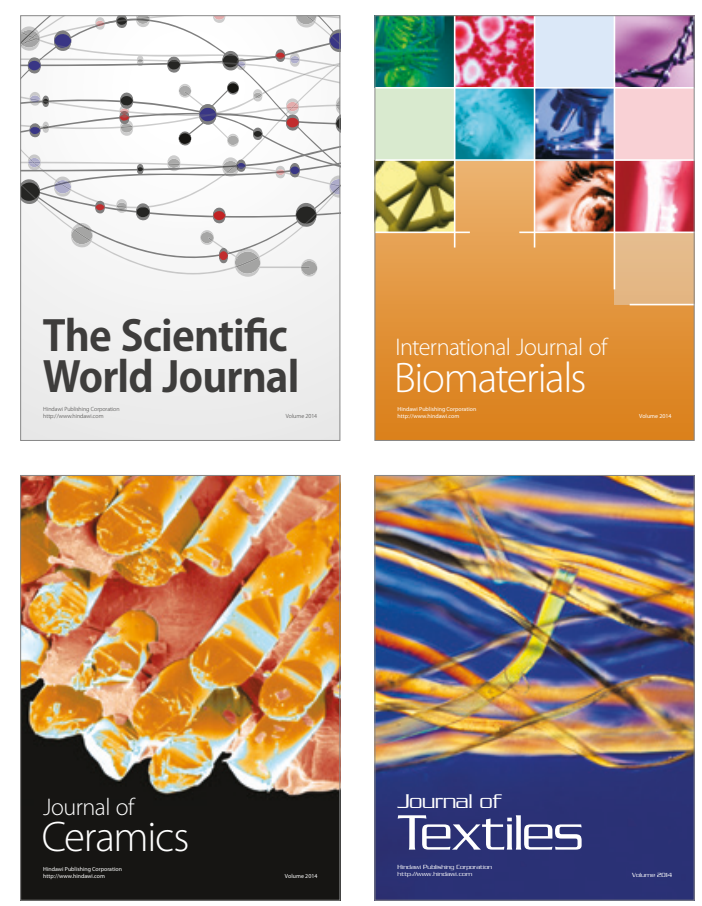